\title{
Stress, myocardial infarction, and the "tako-tsubo" phenomenon
}

\author{
K A Connelly, A I Maclsaac, V M Jelinek
}

Heart 2004;90:e52 (http://www.heartjnl.com/cgi/content/full/90/9/e52). doi: 10.1136/hrt.2004.038851

\begin{abstract}
Emotional distress as a trigger for acute myocardial infarction is beginning to gain credibility as it is recognised that traditional risk factors can account for only half of all myocardial infarctions. Here, three cases of myocardial infarction are presented in the setting of an acute emotional stressor, with coronary angiography showing only minimal coronary artery disease. In all cases striking wall motion abnormalities, mimicking a "tako-tsubo", were noted with complete resolution within 30 days. This pattern suggests tako-tsubo-like transient left ventricular dysfunction.
\end{abstract}

$\mathrm{T}$ here is increasing epidemiological evidence that acute extraordinary stress can precipitate acute myocardial infarction or lethal cardiac arrhythmias. This has been seen in the context of earthquakes, ${ }^{1}$ missile attacks, ${ }^{2}$ and the televising of soccer penalty shootouts. ${ }^{3}$

Clinicians often dismiss acute stress as a triggering mechanism for myocardial infarction because of the possibility that such events are fortuitous. We report three cases of acute myocardial infarction occurring in young women. Emotional stress immediately preceded acute ST elevation myocardial infarction in two and non-ST elevation myocardial infarction in the third. Coronary angiography within 24 hours of the acute attack in two cases and seven days later in the third case showed minimal coronary artery disease with major regional left ventricular impairment. In all cases, severely depressed left ventricular function returned to normal. The pattern suggests "tako-tsubo" -like transient left ventricular dysfunction.

\section{CASE REPORTS}

\section{Case 1}

A 49 year old woman presented with chest pain, which started during a heated meeting involving a sexual harassment case. At presentation, 10 hours after onset of pain, she was in cardiogenic shock with ECG indicating anterior ST elevation myocardial infarction. She was thrombolysed with reteplase and transferred to a tertiary referral centre. Troponin I rose to $11.8 \mu \mathrm{g} / \mathrm{l}$ (normal laboratory reference range $<0.16$; Bayer ADVIA Centaur, Bayer Corporation, Tarrytown, New York, USA). Anterior Q waves developed on the ECG. Coronary angiography showed minor disease in the left anterior descending artery but no other coronary artery disease (fig 1). Left ventriculography showed anteroapical akinesis and preserved basal function. End diastolic pressure was $26 \mathrm{~mm} \mathrm{H}$ (figs 2 and 3). Treatment was initiated with aspirin, coumarin, $\beta$ blockade, hydroxymethyl glutaryl coenzyme A (HMG-CoA) reductase inhibitor, and angiotensin converting enzyme inhibitor. Follow up echocardiography showed normal left ventricular function.

\section{Case 2}

A 58 year old woman developed chest pain immediately after an argument, which resulted in a permanent family break up. Her ECG showed ST elevation in leads I and aVL and ST depression in leads 2, 3, and aVF. Troponin I rose to $8.0 \mu \mathrm{g} / \mathrm{l}$ (normal laboratory reference range $<0.16 \mu \mathrm{g} /$; Bayer ADVIA Centaur). Coronary angiography showed only minor coronary artery disease but anterolateral, lateral, and posterolateral akinesis with an end diastolic pressure of $25 \mathrm{~mm} \mathrm{Hg}$. She was treated with aspirin, $\beta$ blockade, HMG-CoA reductase inhibitor, and angiotensin converting enzyme inhibitor. Follow up echocardiography showed normal left ventricular function.

\section{Case 3}

A previously well 40 year woman, while driving her three children, was involved in a rear end, low speed collision. There was no direct chest trauma. After the accident she became extremely distressed and cried. She was assessed at the scene of the accident but no injuries were found. She presented to hospital some hours after the accident extremely short of breath. ECG showed widespread T wave inversion, chest radiography showed interstitial oedema, and an echocardiogram showed anteroapical akinesis. Troponin I rose to $0.20 \mu \mathrm{g} / \mathrm{l}$ (normal laboratory reference range $<0.16 \mu \mathrm{g} / \mathrm{l}$; Bayer ADVIA Centaur). Coronary angiography seven days later showed normal coronary arteries and normal left ventricular function, but spasm of the right coronary artery was noted during the angiogram. The end diastolic pressure was $7 \mathrm{~mm} \mathrm{Hg}$.

\section{DISCUSSION}

All three cases share in common a severe emotional stressor followed by the onset of chest pain, unequivocal myocardial

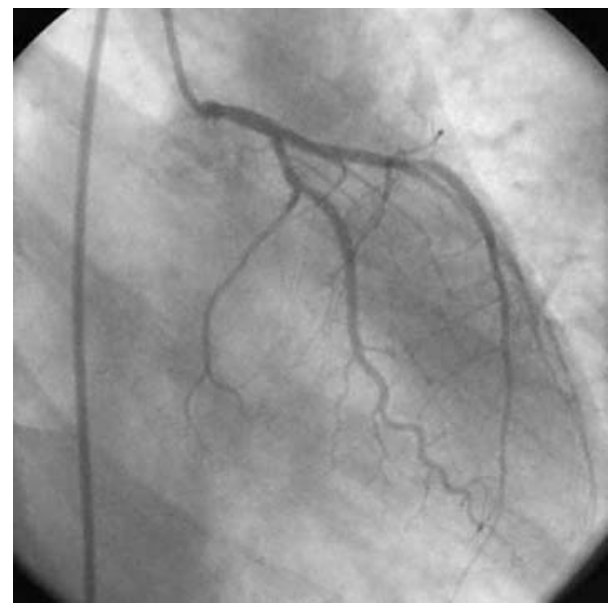

Figure 1 Coronary angiogram showing minor disease in the left anterior descending artery but no other coronary artery disease. 


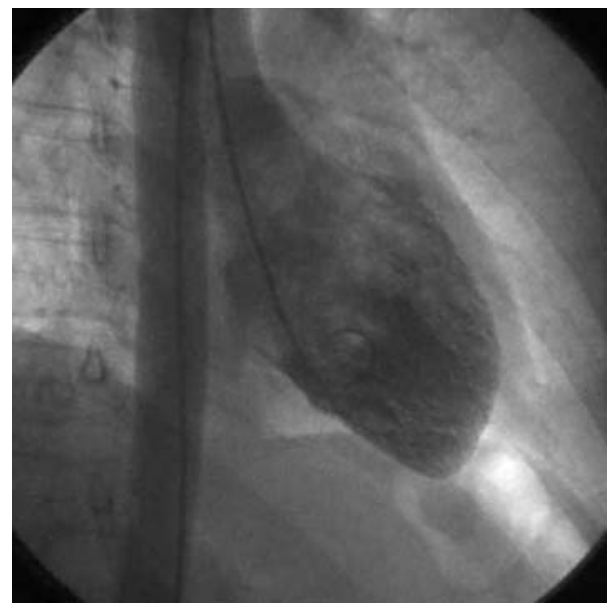

Figure 2 Left ventriculogram showing anteroapical akinesis and preserved basal function (diastole).

infarction with significant wall motion abnormalities, no significant coronary artery disease observed at coronary angiography, and rapid resolution of those wall motion abnormalities. In the authors' opinion, the severity of the wall motion abnormalities and the major lack of coronary artery disease are the striking features.

In 1991, Dote and colleagues ${ }^{4}$ proposed the term takotsubo-like left ventricular dysfunction to describe the syndrome of transient left ventricular dysfunction with chest symptoms, ECG changes, and minimal myocardial enzyme release mimicking acute myocardial infarction but without significant coronary artery disease. The term tako-tsubo was used, as the left ventriculogram looks like a tako-tsubo, an instrument used to trap octopuses in Japan (tako = octopus, tsubo $=$ pot $)$.

\section{Diagnosis}

Kurisu and colleagues ${ }^{5}$ have delineated the clinical characteristics of this syndrome, although formal diagnostic criteria have never been validated because of the rarity of this condition:

- age of onset is usually $>60$ years

- there is a large female predominance

- a significant proportion of the patients experience an acute emotional stressor before the onset of symptoms(>30\%)

- ECG usually shows ST segment elevation or T wave inversion, especially in the precordial leads (V3-6)

- creatinine kinase increases are modest, averaging 539 $( \pm 631) \mathrm{IU} / \mathrm{l}$

- coronary angiography shows tako-tsubo-like left ventricular dysfunction, shown by hypokinesis or akinesis from the mid-portion of the anterior wall to the apex and hyperkinesis of the basal area

- coronary artery disease is absent at coronary angiography

- regional wall motion abnormalities return to normal within several weeks of the index event.

The authors believe the above cases had all these features. The age of two of the women is much younger than that reported in the literature previously. Cardiogenic shock has been reported also, as occurred in the first case. ${ }^{6}$ While acute atherosclerotic plaque rupture followed by the formation of an occlusive thrombus and resultant myocardial stunning cannot be definitively excluded, the striking absence of significant coronary artery disease, the rapid resolution of

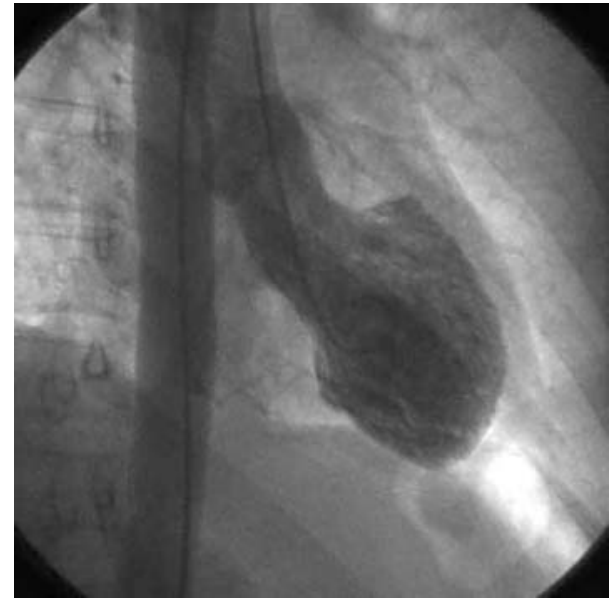

Figure 3 Further left ventriculogram (systole).

wall motion abnormalities, the female predominance, and precipitation by an acute emotional stressor make coronary artery disease unlikely.

\section{Pathophysiology}

No precise cause has as yet been elucidated to explain the transient nature of this phenomenon. Possible causes are coronary artery disease, multivessel coronary artery spasm, acute myocarditis, and increased plasma catecholamines. Kurisu and colleagues ${ }^{5}$ have undertaken an extensive examination of 30 Japanese patients: 28 women and two men with a mean age of 70 years. They measured plasma catecholamine concentration within 24 hours of onset (six patients), tested spasm provocation with ergonovine and acetylcholine (14 patients), recorded coronary angiograms (all subjects), took endomyocardial biopsies (three patients), and measured viral titres (seven patients). Although no clear cause was found in this group, coronary spasm provocation testing was positive in 10 of 14 patients and multivessel spasm was induced in six. Interestingly in this group, bronchial asthma and rheumatoid arthritis were overrepresented but no clear association or causal relation was found.

Ako and colleagues ${ }^{7}$ postulated that the same mechanisms that induce the tako-tsubo phenomenon may lead to the left ventricular dysfunction that is seen in cases of subarachnoid haemorrhage or brain death. This is of some importance given the lack of organ donors and the reliance on a normal echocardiogram before organ harvest. Patients with the takotsubo asynergy should be targeted as potential donors given the transient nature of the dysfunction.

\section{Conclusion}

These three cases all share in common an acute emotional stress that precipitated acute myocardial infarction. The cause is unclear but it is notable that wall motion abnormalities resolved rapidly in all three cases in this group of patients in whom acute plaque rupture and thrombus formation were unlikely. As a result we are forced to consider the possibility that coronary artery spasm may have resulted in the wall motion abnormalities described. In patients presenting with unequivocal myocardial infarction with no significant coronary artery disease and a left ventriculogram mimicking a tako-tsubo, this unusual disorder should be considered, as presumably such patients have an excellent prognosis and may require different treatments and have different medicolegal implications from myocardial infarction related to ischaemic heart disease. 


\section{ACKNOWLEDGEMENTS}

Dr Kim Connelly is supported by a postgraduate research scholarship from the National Heart Foundation, Australia.

\section{Authors' affiliations}

K A Connelly, A I Maclsaac, V M Jelinek, Department of Cardiology, St Vincent's Hospital Melbourne, Fitzroy, Victoria, Australia

Correspondence to: Dr Kim A Connelly, Cardiac Investigation Unit, St Vincent's Hospital, PO Box 2900, Fitzroy, Victoria 3065, Australia; connelka@svhm.org.au

Accepted 30 April 2004

\section{REFERENCES}

1 Leor J, Kloner RA. The Northridge earthquake as a trigger for acute myocardial infarction. Am J Cardiol 1996;77:1230-2.

2 Kark JD, Goldman S, Epstein L. Iraqi missile attacks on Israel. JAMA 1995:273:1208-10.

3 Witte DR, Bots ML, Hoes AW, et al. Cardiovascular mortality in Dutch men during 1996 European football championship: longitudinal population study. BMJ 2000;321:1552-4.

4 Dote K, Sato $\mathrm{H}$, Tateishi $\mathrm{H}$, et al. Myocardial stunning due to simultaneous multivessel coronary spasm: a review of 5 cases. J Cardiol 1991:21:203-14.

5 Kurisu S, Sato H, Kawagoe T, et al. Tako-tsubo-like left ventricular dysfunction with ST-segment elevation: a novel cardiac syndrome mimicking acute myocardial infarction. Am Heart J 2002; 143:448-55

6 Nyui N, Yamanaka O, Nakayama R, et al. "Tako-tsubo" transient ventricular dysfunction. Jpn Circ J 2000;64:715-9

7 Ako J, Honda Y, Fitzgerald PJ. Tako-tsubo-like left ventricular dysfunction. Circulation 2003; 108:e158. 